\title{
Disentangling the response of forest and grassland energy exchange to heatwaves under idealized land-atmosphere coupling
}

\author{
C. C. van Heerwaarden ${ }^{1}$ and A. J. Teuling ${ }^{2}$ \\ ${ }^{1}$ Max Planck Institute for Meteorology, Hamburg, Germany \\ ${ }^{2}$ Hydrology and Quantitative Water Management Group, Wageningen University, Wageningen, the Netherlands \\ Correspondence to: C. C. van Heerwaarden (chiel.vanheerwaarden@mpimet.mpg.de)
}

Received: 13 March 2014 - Published in Biogeosciences Discuss.: 28 April 2014

Revised: 24 September 2014 - Accepted: 27 September 2014 - Published: 13 November 2014

\begin{abstract}
This study investigates the difference in land-atmosphere interactions between grassland and forest during typical heatwave conditions in order to understand the controversial results of Teuling et al. (2010) (hereafter T10), who found the systematic occurrence of higher sensible heat fluxes over forest than over grassland during heatwaves. With a simple but accurate coupled land-atmosphere model, we show that existing parametrizations are able to reproduce the findings of T10 for normal summer and heatwave conditions. Furthermore, we demonstrate the sensitivity of the coupled system to changes in incoming radiation and early-morning temperature typical for European heatwaves.

Our results suggest that the fast atmospheric control of stomatal resistance can explain the observed differences between grassland and forest. The atmospheric boundary layer has a buffering function therein: increases in stomatal resistance are largely compensated for by increases in the potential evaporation due to atmospheric warming and drying.

In order to disentangle the contributions of differences in several static and dynamic properties between forest and grassland, we have performed a virtual experiment with artificial land-use types that are equal to grassland, but with one of its properties replaced by that of forest. From these, we confirm the important role of the fast physiological processes that lead to the closure of stomata. Nonetheless, for a full explanation of T10's results, the other properties (albedo, roughness and the ratio of minimum stomatal resistance to leaf-area index) play an important but indirect role; their influences mainly consist of strengthening the feedback that leads to the closure of the stomata by providing more energy that can be converted into sensible heat. The model experi-
\end{abstract}

ment also confirms that, in line with the larger sensible heat flux, higher atmospheric temperatures occur over forest.

As our parametrization for stomatal resistance is empirical rather than mechanical, our study stresses the demand for a better mechanistic understanding of physiological processes in plants.

\section{Introduction}

There are strong indications that the intensity and frequency of midlatitude heatwaves has increased over the last decades, but the degree to which this can be attributed to human influence on the climate is uncertain (IPCC, 2013). Since local land surface conditions can strongly impact temperatures during heatwaves (Fischer et al., 2007; Miralles et al., 2012), any changes in land surface conditions, for instance through land-use change, have the potential to impact temperature extremes. Probably the most striking example of land-use change in the world is deforestation; in many parts of the world, forests have been converted into grassland over the last centuries (e.g., Christidis et al., 2013). Despite the fact that deforestation has been recognized as an important driver of local climate change (Davin and de Noblet-Ducoudré, 2010; Bonan, 2008), its effect on heatwaves is still poorly understood. Until now it has been unclear whether forests reach higher or lower temperatures than grassland during warm summer conditions or heatwaves (Zaitchik et al., 2006; Teuling et al., 2010; Anderson et al., 2010). One of the major open questions is how and to what extent land-use affects temperature extremes during heatwaves. This is shown 
to depend strongly on feedbacks between the land surface and the atmospheric boundary layer (Stap et al., 2014).

The recent study of Teuling et al. (2010) (hereafter T10) showed that, during the early stages of a heatwave, the sensible heat fluxes above forests can far exceed those over grassland, despite the common belief that forests, with their deeper root systems, would maintain higher evapotranspiration rates and thus dampen the strength of heatwaves (Bonan, 2008). To illustrate this, Fig. 1 shows the composite relationship between midday temperature and incoming shortwave radiation and the preceding midday (09:00-13:00 UTC) sensible and latent heat fluxes over all European forest and grassland FLUXNET sites with long-term observations taken from T10. We can induce from this figure that forest amplifies its near-surface temperature by increasing its sensible heat flux under high temperatures and high incoming shortwave radiation, whereas grassland maintains a more constant flux. This, however, does not immediately imply that the highest temperatures occur over forest, as the temperature increase due to the extra sensible heat flux is (partly) offset by increased mixing above the canopy due to the higher roughness of forest. Furthermore, we find that forest has an optimum in the evapotranspiration rate for maximum temperatures between 294 and $300 \mathrm{~K}$, whereas grassland still increases with maximum temperature within this range.

In this paper, we aim at improving our understanding of the mechanisms that drive the behavior reported by T10 and Fig. 1 by means of a modeling experiment of the coupled land-surface-atmospheric-boundary-layer system. In order to provide a theoretical framework for our analysis, we start this study by explaining the differences in feedback loops that regulate the atmospheric control on evapotranspiration between forest and grassland (Sect. 2).

For our modeling experiment we use a coupled model that consists of a bulk parametrization for the atmospheric boundary layer, a land surface scheme, a force-restore soil model, and a basic radiation scheme (van Heerwaarden et al., 2010a, b; Vilà-Guerau de Arellano et al., 2012). The essence of our experiment is that we model a typical day in order to show that the modeling of fast processes is sufficient to explain the first-order response of the coupled land-atmosphere system to heatwave conditions. Our focus is thus on short heatwaves, because in longer heatwaves the depletion of soil moisture plays an important role (Fischer et al., 2007; Miralles et al., 2014). The relevant fast processes in this study are the atmospheric turbulence, the opening and closure of the stomata of the vegetation, and the response time of the surface temperature, which all have timescales less than tens of minutes. The model and the experiments are described in Sect. 3. Our modeling experiment consists of three phases.

First, we evaluate our model against observations reported in T10 for normal summer and heat wave conditions (Sect. 4.1). Then, we perform a sensitivity study on the external forcings and show how the surface energy balance, atmospheric temperature and humidity, and the boundary layer

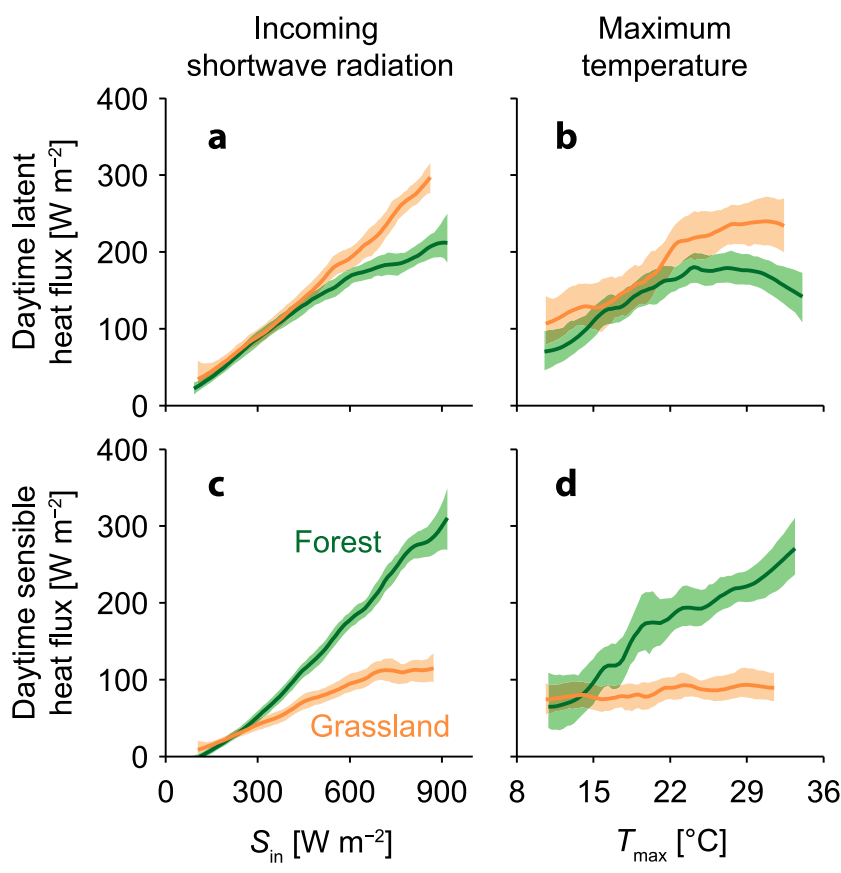

Figure 1. Observed midday sensible heat fluxes $H$ (a) and latent heat fluxes $L E$ (b) over forest and grassland sites as a function of daily maximum air temperature and averaged incoming shortwave radiation. Curves have been derived using locally weighted polynomial regression (LOESS) on all midday data (09:00-13:00 UTC), heatwave days included, in the months June-August for all European FLUXNET sites analyzed in T10. Uncertainty bounds reflect 5 and $95 \%$ percentiles of the LOESS regression as determined by bootstrapping. See supplementary information in T10 for more information.

height respond to changes in the incoming radiation and the large-scale temperature forcing (Sect. 4.2). In Sect. 4.3 we quantify the importance of the feedbacks between the landsurface and the atmospheric boundary layer. To conclude, we analyze the differences between forest and grassland in detail by comparing the relative importance of properties of the land surface that are different between forest and grass: the albedo, the physiological response of the vegetation, the ratio of the leaf-area index to the minimum resistance, and the roughness (Sect. 4.4).

In our model, we parametrize the response of the vegetation to the atmosphere in an empirical way following Jarvis (1976), similar to the parametrization of transpiration in the majority of the numerical weather prediction models (e.g., Noilhan and Mahfouf, 1996; Ek et al., 2003). In such parametrizations, individual vegetation species are combined in classes, such as grassland, cropland, deciduous forest, needleleaf forests, etc. This means that this type of parametrization is assumed to only perform well on the landscape scale, where the variations among different species within the same class average out. In this paper, for simplicity we deal with grassland and forest only. This is justified by the 
observation of Teuling et al. (2010), who showed the clustering of grassland and forest sites in their respective response to heatwave conditions. Wherever we discuss model results, grassland and forest refer thus to their respective classes in the parametrization.

Although these class-based parametrizations have been tuned to give a good performance in numerical weather prediction, they are empirical, not mechanical. The mechanisms within the plant that drive the response to the air temperature and vapor pressure deficit are still poorly understood (Monteith, 1995), and contradicting descriptions can be found in the literature (Streck, 2012). Although Oren et al. (1999) show that many leaf stomata reduce their aperture under the presence of dry air, studies at the landscape scale show for instance maintained evapotranspiration during dry spells in mountainous grasslands (Brilli et al., 2011). In addition, detailed measurements among different crops show very species-specific behavior (van de Boer et al., 2014). Our study will therefore focus on the landscape scale and on the relative importance of the plant physiological behavior in comparison to the other more static vegetation properties.

\section{Land-atmosphere coupling over grassland and forest}

The atmospheric control on evapotranspiration works on short timescales, due to the turbulent nature of the transport and mixing in the atmospheric boundary layer. Therefore, during daytime, heat and moisture are efficiently transported away from the surface and mixed throughout this layer on timescales on the order of tens of minutes. Over wellwatered grasslands, with low dynamics in the stomatal resistance, this leads to a system with three dominant negative feedback loops that are shortly summarized here (see Fig. 2). For a complete description, we refer the reader to van Heerwaarden et al. (2009).

First, there is the heating feedback, where heating of the atmosphere, either directly or indirectly through entrainment by boundary layer growth, increases the capacity for water and therefore the potential evaporation. Second, there is the drying feedback. Throughout the day, the turbulent atmospheric boundary layer grows and therefore brings in dry air from the free atmosphere above. The drying of the air reduces the degree to which the atmospheric capacity for water has been met and therefore enhances the potential evaporation. Third, the moistening feedback takes into account that the evapotranspiration reduces when the atmosphere moistens due to evapotranspiration. These three feedback loops direct the system towards a state defined as equilibrium evaporation (Raupach, 2000, 2001; van Heerwaarden et al., 2009). In this representation of the system, we conclude that, on short timescales, changes in the actual evapotranspiration rate are driven by changes in the temperature and humidity in the atmospheric boundary layer and therefore in the potential evaporation rate.
Thus far, the feedback loops in the system have not been take into account the response of the vegetation to the atmospheric flow and therefore implicitly assumed that the stomatal resistance is constant in time, such that the atmosphere is the only control on evapotranspiration. This, however, is a simplification that only applies to well-watered grassland. For most natural vegetation the feedback loops are more complex and an additional connection is added: the response of the stomatal resistance to the atmospheric temperature and humidity. Leaf stomata are known to react strongly to increasing dryness of the air by letting the trees close their stomata. The stomatal resistance, to which the evapotranspiration rate is inversely proportional, thus increases under a larger vapor pressure deficit $(V P D)$ (Oren et al., 1999). Furthermore, there are indications that vegetation has an optimum temperature beyond which the stomatal resistance decreases (Noilhan and Mahfouf, 1996). The plant physiology has a dramatic effect on the behavior of the system; in the simplified system, warming and drying lead to an increase in evapotranspiration, whereas in a coupled system where the stomatal resistance response to the atmosphere, there is a competition between the enhancement of the potential evaporation and the increase in the stomatal resistance. As soon as the latter effect becomes stronger, all feedback loops change from negative to positive: more heating and drying lead to a higher stomatal resistance and less evapotranspiration, which in turn leads to more heating and drying. We show in Sect. 4.2 that the shift of the system from one that evolves towards equilibrium evaporation to one that evolves towards very low evapotranspiration rates leaves a distinct signal in the results.

\section{Methods}

\subsection{Coupled land-atmosphere model}

This study uses a simple but accurate model of the coupled land-atmosphere system that has been explained in detail in van Heerwaarden et al. (2010a). The atmospheric part of the model is a bulk model for the convective atmospheric boundary layer (Tennekes, 1973). Furthermore, it has a simplified radiation parametrization that provides the incoming short- and longwave radiation to the system. The surface energy balance at the land surface is solved using the Penman-Monteith equation (Monteith, 1965), and the heat and moisture transport in the soil is described using a forcerestore model (Noilhan and Mahfouf, 1996).

Since this study is about the differences between grassland and forest, we focus here only on the properties that control these differences and how these are implemented in the model. The albedo $\alpha(-)$ is used in the calculation of the net shortwave radiation $S_{\text {net }}\left(\mathrm{W} \mathrm{m}^{-2}\right)$ following

$S_{\text {net }}=(1-c c)(1-\alpha) S_{\text {in }}$, 


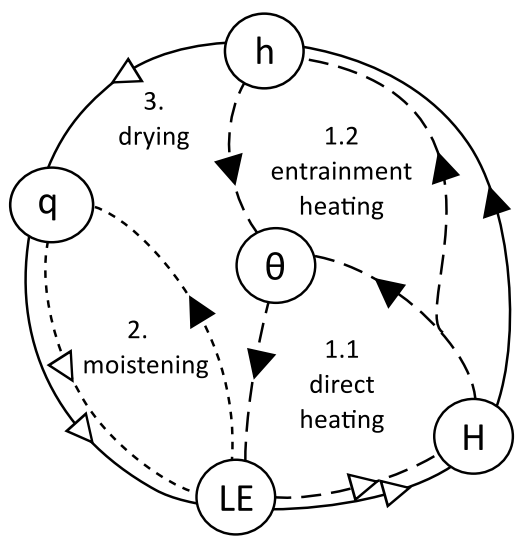

a) without stomatal resistance feedback

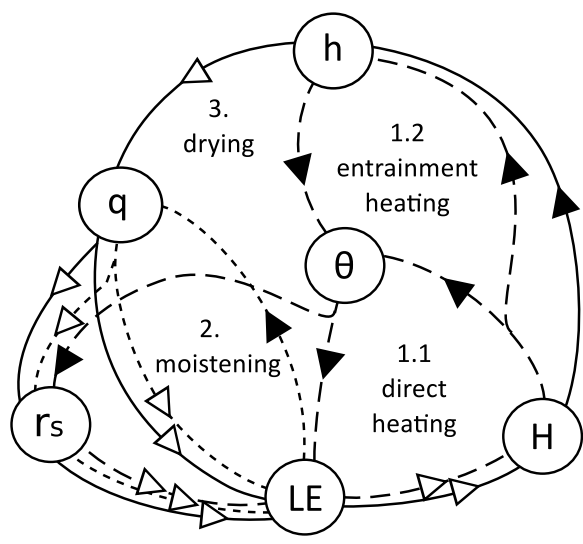

b) with stomatal resistance feedback

Figure 2. Overview of the most relevant feedback loops between the land surface and the atmospheric boundary layer for forest and grassland without and with the active role of the plant physiology (left diagram comes from van Heerwaarden et al., 2009). Closed triangles show positive correlations, and open triangles negative ones. Each line style describes a distinct feedback loop. $L E$ is the evapotranspiration, $H$ is the sensible heat flux, $\theta$ and $q$ are the potential temperature and the specific humidity of the atmospheric boundary layer, $h$ is the height of that layer and $r_{\mathrm{s}}$ is the stomatal resistance.

where $S_{\text {in }}$ is the incoming shortwave radiation and $\left(\mathrm{W} \mathrm{m}^{-2}\right)$ $c c$ is the cloud cover $(-)$. The albedo therefore influences the amount of net radiation available for the sensible, latent and soil heat flux. Note that we only take the shortwave effect of clouds into account.

The roughness lengths $z_{0} \mathrm{~m}$ and $z_{0 \mathrm{~h}}(\mathrm{~m})$ enter in the calculation of the drag coefficient (Paulson, 1970), to which the aerodynamic resistance, $r_{\mathrm{a}}\left(\mathrm{s} \mathrm{m}^{-1}\right)$, is inversely proportional. The aerodynamic resistance is included in the evapotranspiration calculation:

$L E \propto \frac{1}{r_{\mathrm{a}}+r_{\mathrm{s}}}$,

where $L E\left(\mathrm{~W} \mathrm{~m}^{-2}\right)$ is the latent heat flux or evapotranspiration and $r_{\mathrm{s}}\left(\mathrm{s} \mathrm{m}^{-1}\right)$ the stomatal resistance.

Two main properties determine the calculation of the stomatal resistance $r_{\mathrm{s}}$ : the ratio of the minimal stomatal resistance to the leaf-area index, and the response of the stomata to environmental conditions. The former property determines to which extent potential evaporation (at $r_{\mathrm{s}}=0 \mathrm{~s} \mathrm{~m}^{-1}$ ) can be met, whereas the latter takes into account the response of the leaf stomata to atmospheric temperature and humidity. The $r_{\mathrm{s}}$ is calculated following Jarvis (1976):

$r_{\mathrm{s}}=\frac{r_{\mathrm{s}, \min }}{L A I} f_{1}^{-1}\left(S_{\mathrm{in}}\right) f_{2}^{-1}(w) f_{3}^{-1}(V P D) f_{4}^{-1}\left(T_{\mathrm{a}}\right)$,

where $f_{n}$ are dimensionless correction functions for a certain variable, $w$ is the volumetric soil moisture $\left(\mathrm{m}^{3} \mathrm{~m}^{-3}\right)$ and $T_{\mathrm{a}}$ $(\mathrm{K})$ is the atmospheric temperature at the vegetation level. The response function $f_{3}$ to $V P D(\mathrm{hPa})$ can be described by

$f_{3}=e^{-g_{\mathrm{D}} V P D}$, where $g_{\mathrm{D}}\left(\mathrm{hPa}^{-1}\right)$ is an empirical constant that describes the strength of the response of the vegetation to the vapor pressure deficit.

The response function $f_{4}$ to atmospheric temperature (Noilhan and Mahfouf, 1996) is

$f_{4}=1-0.0016\left(298-T_{\mathrm{a}}\right)^{2}$.

The other correction functions are discussed in van Heerwaarden et al. (2010a).

In the Jarvis parametrization, the correction functions are assumed to be independent of each other. In reality, however, there is a strong correlation between the atmospheric temperature and the vapor pressure deficit, since temperature is the main driver of the $V P D$ under high-temperature conditions (van Heerwaarden et al., 2010a). As the correction functions of the Jarvis parametrization and the associated parameters are purely empirical and there exists a correlation between temperature and $V P D$, tuning of the parametrization does not necessarily give a unique set of correction functions. The possibility of multiple solutions stresses the fact that the parametrization is not mechanically consistent. On the vegetation scale this can lead to serious errors (van de Boer et al., 2014), but on the landscape scale the performance has been shown to be good under very different conditions (e.g., Noilhan and Mahfouf, 1996; van Heerwaarden et al., 2010a, b; Miralles et al., 2014).

\subsection{Modeling experiment}

In our modeling experiment, we focus on the daytime conditions and the response of vegetation to heat waves on the timescales of turbulence (seconds to minutes). This means that we constrain our model simulations to a single day, as 
this is long enough to draw conclusions on the response of fast processes. The atmospheric temperature, humidity and wind profiles that we provide to the model are representative for western European summer conditions. An overview of the specific parameters for grassland and forest is shown in Table 1 and a detailed list of all parameters is given in Table A1 in the Appendix. A similar approach was followed in van Heerwaarden et al. (2010b), but for the Great Plains in the USA.

As already mentioned in the Introduction, the results of our study are strongly dependent on the chosen properties for forest and grassland. Since both vegetation types encompass a wide range of subspecies that all have their own unique properties and responses to the atmospheric properties, we have chosen pure grassland and broadleaf deciduous forest as our vegetation classes, as those provide a good match with the data of T10 and a broad parameter range for our sensitivity study.

We tune the cloud cover and the soil moisture of the model such that it produces values of the incoming radiation and partitioning between sensible and latent heat fluxes that are consistent with observations in T10. We stress here that our aim is not to exactly reproduce the data but rather to demonstrate the behavior of the system and to make an assessment of the most important links in the coupled system. In Fig. 4 and further, we look at the sensitivity of the system to any change in initial temperature and incoming radiation.

After establishing the mean state that is consistent with T10, we continue by performing a sensitivity study on the incoming radiation by varying the cloud cover and the earlymorning temperature. In order to maintain realistic atmospheric conditions during the sensitivity experiment, we shift the entire atmospheric potential temperature profile and the near-surface soil temperature towards new values, such that the vertical gradients are maintained. Based on this new profile, we perturb the specific humidity, such that we maintain the same initial relative humidity in all our experiments, so as to allow for a fair comparison. Since the model is fast, we can explore a large number of combinations. Within these simulation results, we locate the heat wave conditions that match the shortwave radiation anomaly and temperature anomaly that $\mathrm{T} 10$ has reported.

Then, in order to understand better the importance of the individual properties that distinguishes forest from grassland in our model (albedo, roughness length, stomatal response to $V P D$ and ratio of the minimal resistance to the leaf-area index), we redo our sensitivity study again, but with newly created land-use types that resemble grassland with one of the four properties of forest attached to it. With this approach we can estimate the relative importance of each property and the degree to which the different properties weaken or strengthen each other.
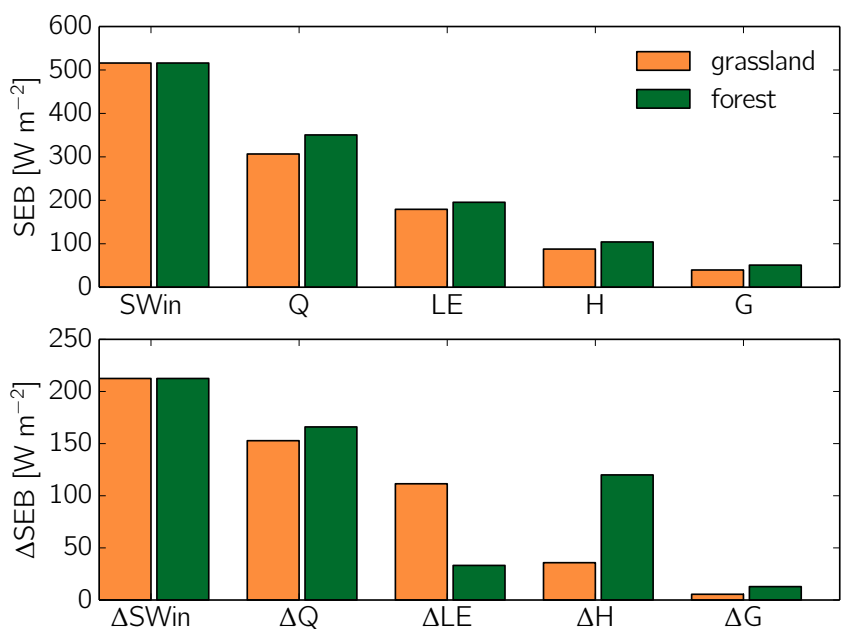

Figure 3. The surface energy balance (SEB) under normal conditions (top panel) and under heat wave conditions (bottom panel) as computed in the modeling experiment. The values are the $10 \mathrm{~h}$ means over the entire duration of the model run. The difference is computed by subtracting the mean state from the heat wave conditions.

\section{Results}

\subsection{Reproduction of the measurements}

The model setup described in Sect. 3 is able to reproduce the most important characteristics of the measurements. Figure 3 shows the surface energy balance under average forcings and under typical heat wave conditions and can be directly compared to Fig. $1 \mathrm{~b}$ and $\mathrm{d}$ in T10. Since we have chosen those values for incoming shortwave radiation and soil moisture contents that reproduce T10's mean state in the best possible way, the match is not surprising. We would like to stress that, due to the large variations in soil types and detailed land uses among the different FLUXNET sites, we have chosen a composite value of soil moisture that merely serves to deliver the correct fluxes. Although the role of soil moisture in prolonged heat waves is evident, these are outside of the scope of this study and covered in detail elsewhere (T10; Seneviratne et al., 2010; Miralles et al., 2014). The heat wave state, which has been achieved by only perturbing the incoming radiation and the early-morning temperature of the mean state, is reproduced well by the model; all modeled anomalies follow the data of T10, and especially the enhanced sensible heat flux over forest of approximately $125 \mathrm{~W} \mathrm{~m}^{-2}$ $\left(121 \mathrm{~W} \mathrm{~m}^{-2}\right.$ in $\left.\mathrm{T} 10\right)$ is reproduced well. This finding implies that the model, and therefore parametrizations in existing numerical weather prediction and climate models, are able to reproduce the response of forests to perturbations in the incoming radiation and temperature, even without accounting for possible soil moisture differences between normal and heatwave conditions. 
Table 1. Model parameters specific for forest and grassland. Values taken from the ECMWF IFS documentation (Cy36r1, Table 8.1) using the mixed crops as the value for grassland and the broadleaf deciduous forest for forest.

\begin{tabular}{llcc}
\hline Variable & Description and units & Grassland & Forest \\
\hline$\alpha$ & surface albedo [-] & 0.21 & 0.13 \\
$z_{0 \mathrm{~m}}$ & roughness length for momentum $[\mathrm{m}]$ & 0.15 & 2 \\
$z_{0 \mathrm{~h}}$ & roughness length for heat and moisture $[\mathrm{m}]$ & 0.015 & 2 \\
$r_{\mathrm{s}, \min } / L A I$ & minimum resistance/leaf-area index $\left[\mathrm{s} \mathrm{m}^{-1}\right]$ & $180 / 3$ & $175 / 5$ \\
$g_{\mathrm{D}}$ & exponent for $V P D$ response $[\mathrm{hPa}-1]$ & 0 & 0.03 \\
\hline
\end{tabular}

\subsection{The sensitivity of grassland and forest to incoming shortwave radiation and temperature}

Figures 4 and 5 show the results of the entire sensitivity study of which the day that is contained in Fig. 3a has been perturbed. Figure 4 illustrates the sensitivity of the net radiation, the evapotranspiration and the sensible heat flux to the incoming radiation and the early-morning temperature for both forest and grassland.

The surface energy balance and the atmospheric properties of grassland change monotonically under changes in the radiation and the early-morning temperature, whereas those of forest display more complex behavior. As already hypothesized in Sect. 2, grassland mostly responds to the changes in the potential evaporation, and an increase in temperature or radiation automatically results in an increase in evapotranspiration, with a uniform sensitivity over the majority of the parameter range. The net radiation is logically mostly sensitive to changes in the incoming shortwave radiation. Nonetheless, a slight reduction in net radiation is observed with increasing temperature ( $5 \mathrm{~W} \mathrm{~m}^{-2}$ over the entire temperature range), which is related to the increase in surface temperature and the consequent increase in the outgoing longwave radiation.

Forest has a maximum in evapotranspiration and a minimum in the sensible heat flux for given high values of incoming radiation (found at an early-morning temperature of $297 \mathrm{~K}$ for an incoming radiation of $500 \mathrm{~W} \mathrm{~m}^{-2}$ until a temperature of $291 \mathrm{~K}$ for $750 \mathrm{~W} \mathrm{~m}^{-2}$ ). At low early-morning temperatures, the increase in potential evaporation related to the higher temperatures is the dominant effect. However, the decrease in actual evapotranspiration due to the higher stomatal resistance is the strongest effect at higher temperatures, resulting in a reduction of evapotranspiration with an increase in early-morning temperature, similar as shown in the observations in Fig. 1b. Over forest, the change in sensible heat flux with early-morning temperature is non-monotonic as well.

In order to explain the observations shown in Fig. 1, we have marked (black dotted lines, indicating the 93 to $105 \mathrm{~W} \mathrm{~m}^{-2}$ interval) the combinations of incoming shortwave radiation and initial temperature that give a constant sensible heat flux over grassland in the same range as that in Fig. 1. Within this range, the sensible heat flux of for- est increases in the direction of heatwave conditions (high temperature and incoming radiation) from approximately $115 \mathrm{~W} \mathrm{~m}^{-2}$ to values more than $200 \mathrm{~W} \mathrm{~m}^{-2}$, while moving to higher values for incoming radiation and initial temperature. This behavior matches very well with what is found in Fig. 1 and reconfirms the feedback mechanisms discussed in Sect. 2.

The differences in surface energy balance between grassland and forest are reflected in the atmospheric boundary layer characteristics (Fig. 5). The shaded region shows the maximum $2 \mathrm{~m}$ temperature that is achieved during the day. Under conditions of low early-morning temperatures and a small amount of incoming radiation, which are found in the bottom left of the plots, the maximum $2 \mathrm{~m}$ temperature is comparable for grassland and forest $(\sim 293 \mathrm{~K}$ for an earlymorning temperature of $283 \mathrm{~K}$ and an incoming shortwave radiation of $500 \mathrm{~W} \mathrm{~m}^{-2}$ ). As we move towards the top right in the plots, and thus to higher early-morning temperatures and more incoming shortwave radiation, the maximum temperature over forest increases considerably faster over forest ( $313 \mathrm{~K}$ ) than over grassland (308 K). In Fig. 4, we have seen that this is due to an increase in the sensible heat fluxes over forest that is not found over grassland.

The changes in the VPD show the increased drying of the atmosphere over the forest (solid blue lines, Fig. 5). While grassland has a range from 12 to $26 \mathrm{hPa}$ over the entire parameter space, the $V P D$ over the forest increases from 13.5 to $38 \mathrm{hPa}$, which is a much wider range than that over grassland.

The occurrence of a maximum evapotranspiration rate with increasing temperature is reflected in the achieved atmospheric boundary layer heights (dashed red lines, Fig. 5). Grassland shows again a monotonic behavior; the boundary layer height increases with increasing incoming shortwave radiation due to the extra available energy, whereas the boundary layer height decreases under rising early-morning temperatures, due to the shift of energy from sensible to latent heating.

The achieved boundary layer heights over forest show a curved line that displays a minimum with respect to earlymorning temperature close to values of $296 \mathrm{~K}$ for high values of incoming shortwave radiation. This minimum is directly related to the maximum evapotranspiration that was found in Fig. 4 and the result of the vegetation-enforced feedback 

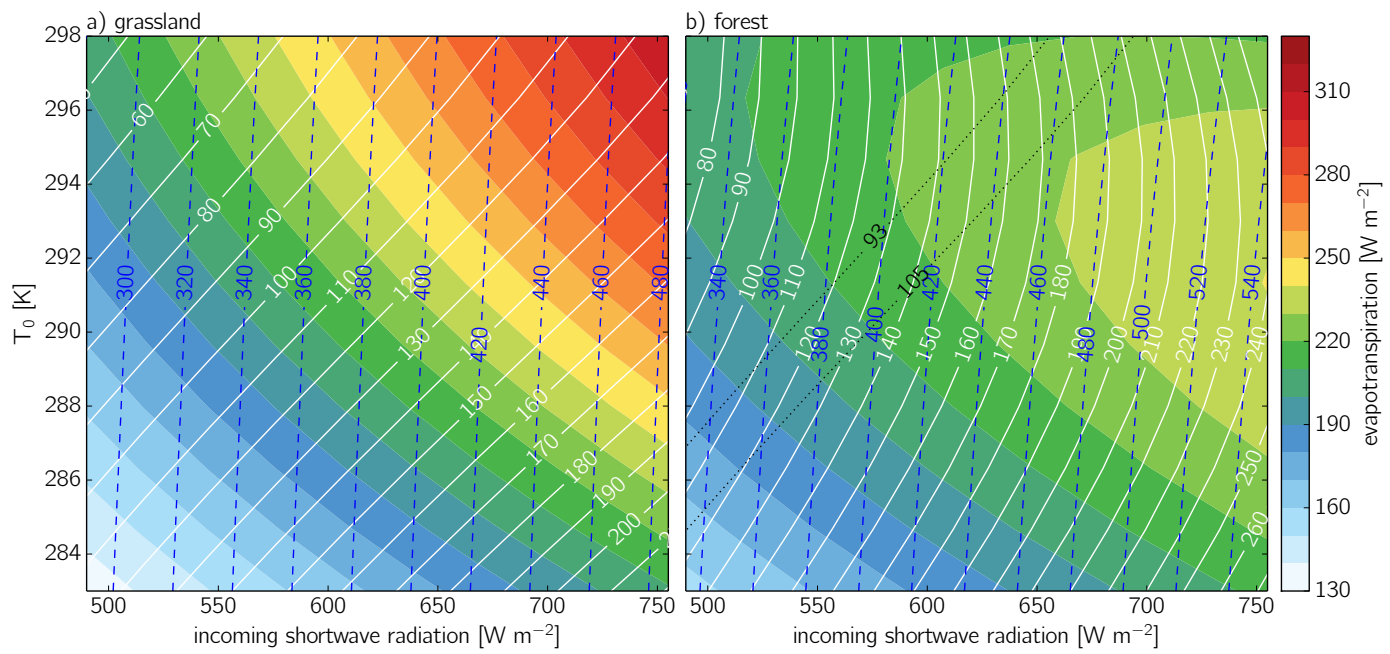

Figure 4. Evapotranspiration or latent heat flux (color band), sensible heat flux (white solid lines) and net radiation (blue dashed lines). The values are the $10 \mathrm{~h}$ means over the entire duration of the model run. The black dotted lines correspond to the range in which grassland gives a constant sensible heat flux with similar magnitudes as those in the observations in Fig. 1.
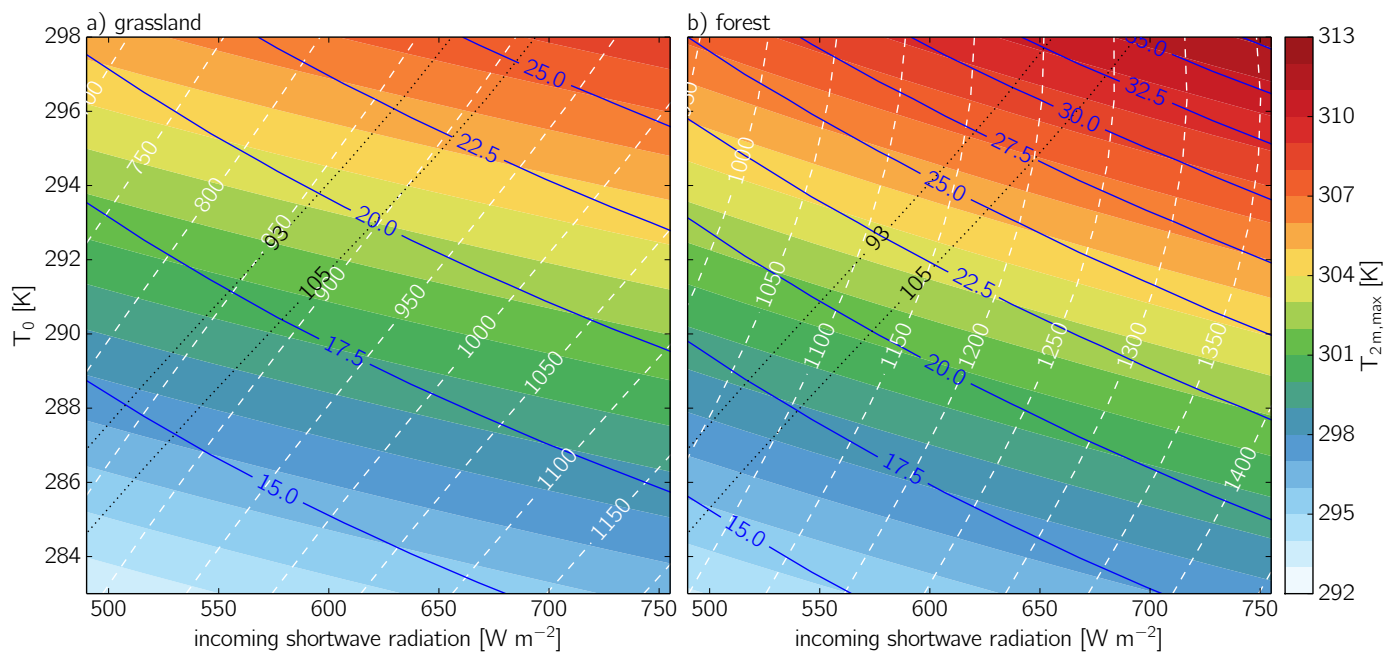

Figure 5. Maximum temperatures (color band), vapor pressure deficit (blue solid lines) and boundary layer height (white dashed lines). The values for the $V P D(\mathrm{hPa})$ and the boundary layer height $(\mathrm{m})$ are the $10 \mathrm{~h}$ means over the entire duration of the model run, and the maximum $2 \mathrm{~m}$ temperature is the maximum over the duration. The black dotted lines correspond to the range in which grassland gives a constant sensible heat flux with similar magnitudes as those in the observations in Fig. 1.

mechanism that is also responsible for the minimum in sensible heat flux found over forest.

\subsection{Estimating the importance of boundary layer feedbacks}

The previous section has shown the different response of the coupled land-atmosphere system for grassland and forest, but the strength of the feedback loops depicted in Fig. 2 remains to be quantified. In other words, we do not know to what extent the boundary layer modifications induced by the properties of forest enhance the heating and dry-out of the atmosphere. In order to find this out, we have performed an experiment in which we put forest underneath an atmosphere that is in equilibrium with grassland and recalculate the surface layer properties, the surface energy balance and the land surface model, making use of the forest properties shown in Table 1.

Figure 6 shows the resulting time evolution of the evapotranspiration and the stomatal resistance under normal and heatwave conditions. Under normal conditions, the time evolution of the evapotranspiration and the stomatal resistance is similar for forest and for forest under a grassland atmosphere. During the heatwave conditions, however, large 


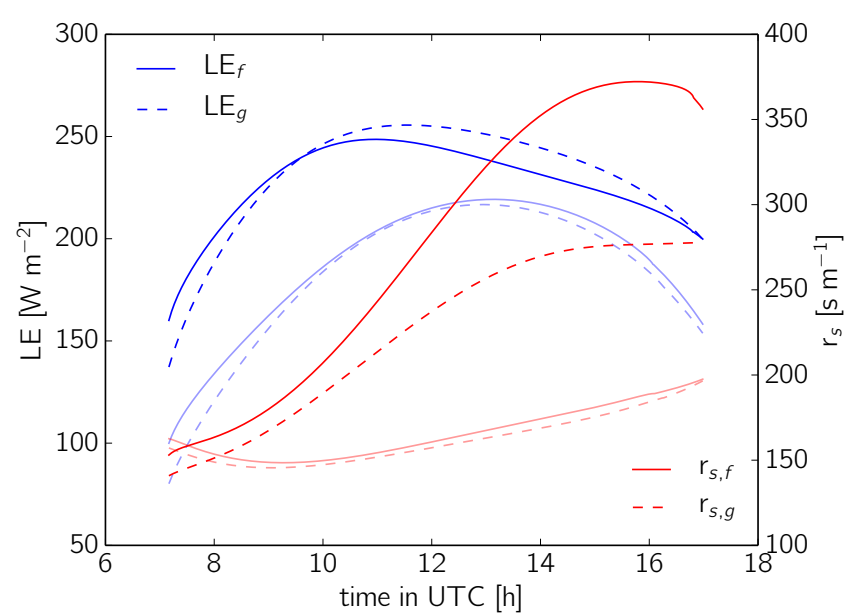

Figure 6. Time evolution of evapotranspiration $L E$ and stomatal resistance $r_{\mathrm{s}}$ under normal conditions (light shades) and heat wave conditions (dark shades).

differences arise. Due to the fact that the atmosphere over forest is warmer and drier, the stomatal resistance of the forest becomes much larger than that of the forest interacting with the atmosphere of grassland. With this finding we clearly demonstrate the enhancing effect of the heating and drying feedback (Fig. 2) on the stomatal resistance. It should be noted that this is only partly reflected in the evapotranspiration rate. An increase in the stomatal resistance that is induced by an increase in the atmospheric temperature and $V P D$ is partly compensated for by an increase in the potential evaporation, due to the higher near-surface temperature and humidity gradients and the extra incoming shortwave radiation.

\subsection{Unraveling the feedback mechanisms}

In the previous section we showed that we are able to reproduce the measurements of T10 with our model. The aim of the current section is to find the relative importance of each of the differences in properties between grassland and forest in creating the big difference between the two land-use types that was found in the measurements of T10. With our model we compare the response of the coupled system to perturbations in incoming radiation and temperature for a set of land-use types. This set contains grassland and forest itself, as well as the newly created virtual land-use types that have the properties of grassland, but with one of the properties replaced by that of forest, such that we can assess the influence of each forest property separately.

Figure 7 shows the difference between grassland and forest, the influence of the four properties separately and the importance of the interaction between the feedbacks, expressed as the nonlinear contribution. Figure 7 a shows the difference in evapotranspiration, maximum temperature and net radi- ation, acquired by subtracting the values of grassland from those of forest, which are shown in Figs. 4 and 5.

The first property that we take into consideration is the albedo (Fig. 7b). The most important change to the system if the albedo of forest is attributed to the grassland is the increase in net radiation for forest, because it has a lower albedo than grassland. The difference increases from 36 to $56 \mathrm{~W} \mathrm{~m}^{-2}$ over the range of shortwave radiation on the horizontal axis, where forest, with its lower albedo, converts more of the extra incoming shortwave radiation to net radiation. The evapotranspiration $\left(\sim 25 \mathrm{~W} \mathrm{~m}^{-2}\right)$ and the maximum temperature $(\sim 0.8 \mathrm{~K})$ show an increase over the entire parameter range but have a low sensitivity to changes in the radiation or early-morning temperature.

The second property is roughness (Fig. 7c). If we increase the roughness of the grassland to that of forest, then the evapotranspiration, maximum temperature and net radiation are affected. In all three variables, the strongest changes occur with a low early-morning temperature and a high incoming shortwave radiation, because here the sensible heat flux is the highest. We suggest that the changes are the effect of a sequence of events that start with an increased mixing near the surface, due to the higher roughness. Subsequently, the nearsurface temperature resembles more that of its overlying atmosphere and drops. Then, the outgoing longwave radiation decreases, resulting in an increase in the available energy for the sensible and latent heat flux. This results in a slightly increased evapotranspiration and sensible heat flux, with an eventual rise in maximum temperature despite the stronger mixing. This interpretation is applicable to the entire range of incoming radiation and early-morning temperatures. All in all, the sensitivity of the system to roughness is relatively low compared to the other properties, which is in line with the previous findings of Hill et al. (2008).

The third property that we study is the response of the stomatal resistance to atmospheric VPD (Fig. 7d). We have already identified the closure of stomata as a potential mechanism to strongly reduce the evapotranspiration (Sect. 2), and Fig. 7 quantifies how this process influences our selected variables. Without major modifications to the net radiation, the replacement of the correction functions of grassland with those of forest results in a large drop in evapotranspiration (up to $100 \mathrm{~W} \mathrm{~m}^{-2}$ ) and a consequent increase in the maximum temperature (more than $2.6 \mathrm{~K}$ ) through an enhanced sensible heat flux over the entire parameter space. The strength of the drying of the atmosphere is reflected in the larger VPD over forest than over grassland (more than $15 \mathrm{hPa}$ ).

The fourth and last property included in the study is the ratio of minimum stomatal resistance to the leaf-area index (see Eq. 3), which is a measure of the maximal potential of the plants to transpire under unstressed soil moisture conditions (Fig. 7e). Since forest has a lower value, it has a lower stomatal resistance under unstressed conditions and therefore higher evapotranspiration rates (30 to 

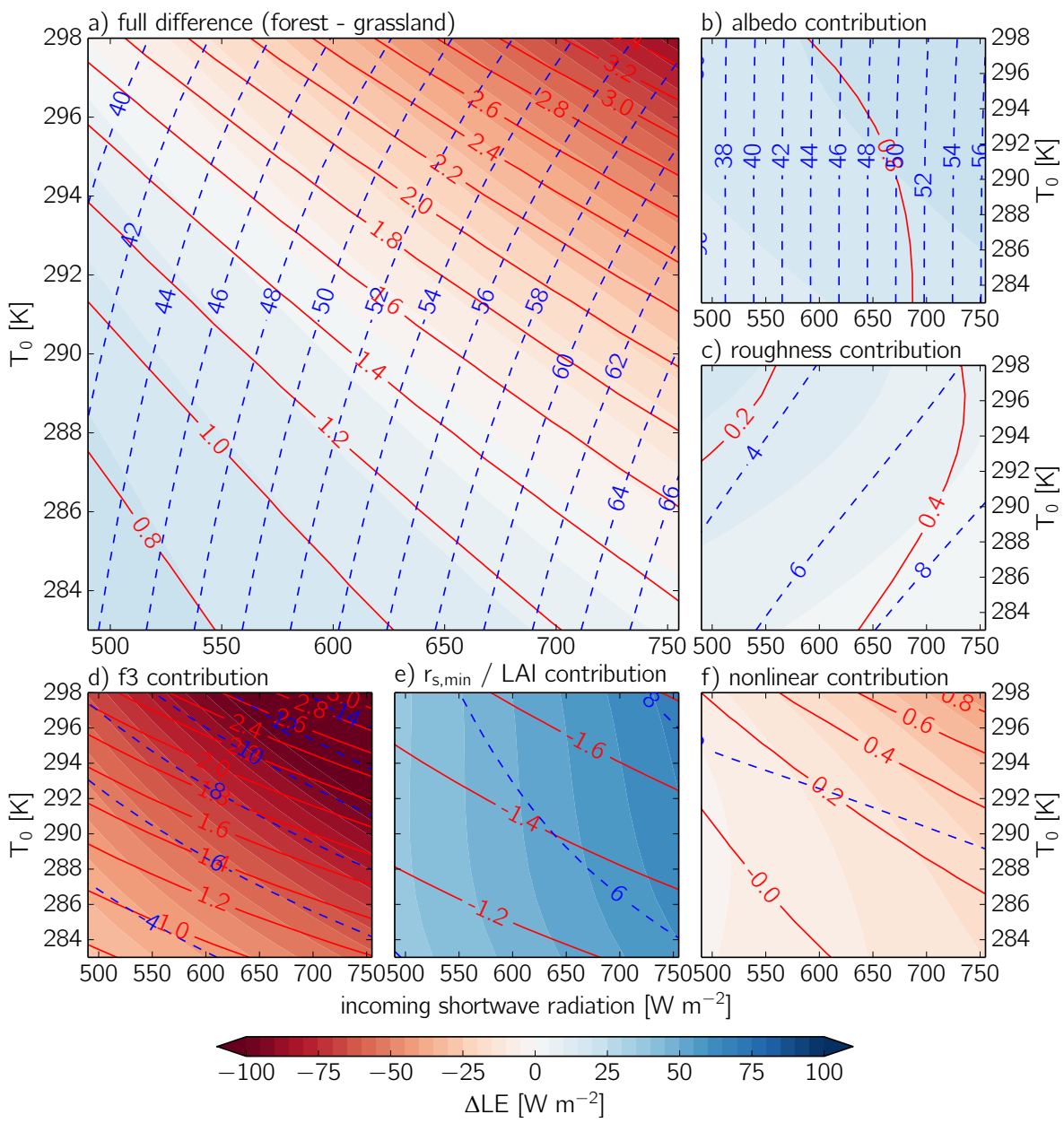

Figure 7. Difference in evapotranspiration (color band), maximum temperature (red solid line) and net radiation (blue dashed line) between forest and grassland as a function of initial temperature and incoming shortwave radiation. Small panels indicate the contribution of individual processes/parameters, such that $a=b+c+d+e+f$. The value $f$ is acquired by subtracting $b+c+d+e$ from $a$. The values for evapotranspiration and net radiation are the $10 \mathrm{~h}$ means over the entire duration of the model run, and the maximum $2 \mathrm{~m}$ temperature is the maximum over the entire duration.

$50 \mathrm{~W} \mathrm{~m}^{-2}$ more than grassland). Hill et al. (2008) have already pointed out the importance of the leaf-area index. The higher evapotranspiration rate results in significantly lower maximum temperatures over forest (more than $1.2 \mathrm{~K}$ less than grassland). The net radiation is insensitive to this parameter.

In order to estimate to which extent the properties counteract or strengthen the effect of the other properties, we have subtracted the four individual effects from the total difference, so that a residual is acquired (Fig. 7f). This residual we label the nonlinear contribution. We find that the reduction of evapotranspiration under increasing temperature and radiation can be more than $50 \mathrm{~W} \mathrm{~m}^{-2}$ larger than the sum of the four individual components. We hypothesize that the increased reduction is related to strong interactions between the effects of albedo and that of the physiological processes. Whereas the extra energy provided by the lower albedo is added to the evapotranspiration in Fig. 7b, this extra energy ends up in the heating in the residual (Fig. 7f). Here, the system has entered the positive feedback loop (Fig. 2), where additional energy leads to an enhanced drying and heating. The additional net radiation of approximately $50 \mathrm{~W} \mathrm{~m}^{-2}$ results in an enhanced reduction in evapotranspiration of the same amount of energy and an additional increase in the maximum temperature of $1 \mathrm{~K}$, almost $25 \%$ of the total difference. The slight increase in net radiation is most likely related to the interplay between the properties related to the vegetation response and the roughness. In this case, the increase in roughness counteracts the highly enhanced surface temperature that is the effect of the physiological processes. Therefore, there is a slight reduction in the outgoing longwave radiation and a corresponding small increase in the net radiation. 


\section{Conclusions}

We have studied the differences in land-atmosphere coupling between grassland and forest during the onset of heat waves by means of a modeling experiment in which a typical summer day for western European conditions was analyzed under normal and under heat wave conditions. With a simple but accurate model that contains the essential processes in the coupled land-atmosphere system (van Heerwaarden et al., 2010a), we are able to reproduce the observations of Teuling et al. (2010) (T10), who showed higher temperatures over forest than over grassland during the early stages of heat waves.

In addition to reproducing the data of T10, we have performed a sensitivity study on the response of forest and grassland to perturbations of the early-morning temperature and radiation in order to mimic the forcings that correspond to heat waves. From this analysis we have learned that both grassland and forest display a monotonically increasing evapotranspiration and sensible heat flux under increasing incoming shortwave radiation, forced by an increase in potential evaporation. The reaction to a rise in earlymorning temperature is more complex. Although grassland shows monotonic increases in evapotranspiration and monotonic decreases in sensible heat flux and atmospheric boundary layer height under increasing early-morning temperatures, forest displays more complex behavior; beyond a critical threshold, the effects of the atmospheric temperature and humidity on stomatal closure are stronger than the effects on the potential evaporation. Therefore, the evapotranspiration no longer increases but instead decreases with increasing temperature, resulting in an increasing sensible heat flux, maximum temperature and atmospheric boundary layer height.

Furthermore, we have repeated the sensitivity study not only for forest and grass but also for a series of virtual landuse types that resemble grassland, with one of its properties replaced by the corresponding property of forest. Here, it was found that the strong temperature increase over forest is primarily driven by the feedback mechanism that leads to an increasingly fast shutdown of evapotranspiration (Fig. 2), related to the stomatal closure of the leaves of trees under heat wave conditions. Even though the response of the stomatal resistance to $V P D$ is important, our results show that all properties are ultimately essential in explaining the results of T10. Mostly the lower albedo of forest plays a crucial role; without the fast physiological processes of the vegetation, the lower albedo mostly enhances the evapotranspiration by providing more energy, whereas all the extra energy is converted into sensible heat when the stomatal response to temperature and humidity is present.

Our results are mainly valid for the onset of heat waves, and we expect the evolution of the soil moisture to take over as the most crucial aspect of the system as soon as the evapotranspiration fluxes start depleting the soil moisture reser- voirs. It is interesting, however, that soil moisture differences are not a prerequisite for the reproduction of the results in $\mathrm{T} 10$, indicating that short-term land-atmosphere interaction rather than soil moisture can explain the observed flux differences.

A logical extension of this study of idealized land-atmosphere coupling is an investigation of the exact role of land-surface heterogeneity. In our study, we have assumed that the surface and the atmosphere are in equilibrium with each other, which requires areas of uniform land use with a radius of at least tens of kilometers (Mahrt, 2000). Many of the western European forests are smaller than this, and therefore the air over forests partly resembles that of grasslands. The results in Sect. 4.3 showed that the increase in stomatal resistance of forests during heat waves is far less when the forest is in contact with an atmosphere that is in equilibrium with grassland. This suppression of the $V P D$-related feedback (Fig. 2) makes the high roughness of forest relatively more important and could explain why several studies have reported lower surface temperatures over forests than over grassland under heat wave conditions.

To conclude, our results suggest that the high temperatures over forest compared to grassland found by T10 are mainly driven by the fast response of the vegetation to the temperature and humidity of the atmosphere. The good news is that the simple parametrizations that are used in our model and in many of the numerical weather prediction models are able to reproduce the heat wave response. Nonetheless, the large magnitude of the temperature rise over forest is the result of a complex interplay of land-surface and atmospheric boundary layer processes. The downside of the type of model that we used is that its parametrizations of stomatal resistance are empirical. This casts doubt on the validity of such models for studies of future climates, where situations can occur that are outside of the tuning range. Our study therefore stresses the need for mechanistic models of physiological processes in plants and for a close collaboration between the biological and hydrometeorological sciences. 


\section{Appendix A: Model parameters}

Table A1 contains an overview of all chosen parameters for our model setup. We have chosen $50^{\circ} \mathrm{N}$ as the representative latitude for central western Europe, the region that T10 studies. Our simulations make use of idealized atmospheric profiles that match the climatology. We maintain the earlymorning relative humidity of our simulations, such that the specific humidity profile changes with the temperature. Our soil parameters describe a standard loamy soil.

Table A1. Initial and boundary conditions for all model runs.

\begin{tabular}{|c|c|c|}
\hline Variable & Description and unit & Values \\
\hline$P_{0}$ & surface pressure $[\mathrm{Pa}]$ & 101300.0 \\
\hline lat & latitude $[\mathrm{deg}]$ & $50^{\circ} \mathrm{N}$ \\
\hline lon & longitude [deg] & $0^{\circ} \mathrm{E}$ \\
\hline doy & day of the year $[-]$ & 182.0 \\
\hline$t_{\text {start }}$ & start time of simulation in local time $[\mathrm{h}]$ & 7 \\
\hline$t_{\mathrm{end}}$ & end time of simulation in local time $[\mathrm{h}]$ & 17 \\
\hline$c c$ & cloud cover $[-]$ & $c c_{\text {input }}$ \\
\hline$w_{\mathrm{g}}$ & volumetric water content top soil layer $\left[\mathrm{m}^{3} \mathrm{~m}^{-3}\right]$ & 0.235 \\
\hline$w_{2}$ & volumetric water content deeper soil layer $\left[\mathrm{m}^{3} \mathrm{~m}^{-3}\right]$ & 0.235 \\
\hline$c_{\text {veg }}$ & vegetation fraction $[-]$ & 0.9 \\
\hline$T_{\text {soil }}$ & temperature top soil layer $[\mathrm{K}]$ & $T_{\text {input }}-3$ \\
\hline$T_{2}$ & temperature deeper soil layer $[\mathrm{K}]$ & $T_{\text {input }}-2$ \\
\hline$a$ & Clapp and Hornberger retention curve parameter [-] & 0.219 \\
\hline$b$ & Clapp and Hornberger retention curve parameter $[-]$ & 4.90 \\
\hline$p$ & Clapp and Hornberger retention curve parameter [-] & 4.0 \\
\hline $\mathrm{CG}_{\text {sat }}$ & saturated soil conductivity for heat $\left[\mathrm{K} \mathrm{m}^{-2} \mathrm{~J}^{-1}\right]$ & $3.56 e-6$ \\
\hline$w_{\text {sat }}$ & saturated volumetric water content $\left[\mathrm{m}^{3} \mathrm{~m}^{-3}\right]$ & 0.472 \\
\hline$w_{\mathrm{fc}}$ & volumetric water content field capacity $\left[\mathrm{m}^{3} \mathrm{~m}^{-3}\right]$ & 0.323 \\
\hline$w_{\text {wilt }}$ & volumetric water content wilting point $\left[\mathrm{m}^{3} \mathrm{~m}^{-3}\right]$ & 0.171 \\
\hline $\mathrm{C} 1_{\text {sat }}$ & coefficient force term moisture $[-]$ & 0.132 \\
\hline $\mathrm{C} 2_{\text {ref }}$ & coefficient restore term moisture $[-]$ & 1.8 \\
\hline$L A I$ & leaf-area index $[-]$ & see Table 1 \\
\hline$r_{\mathrm{s}, \min }$ & minimum resistance transpiration $\left[\mathrm{s} \mathrm{m}^{-1}\right]$ & \\
\hline$z_{0 \mathrm{~m}}$ & roughness length for momentum [m] & \\
\hline$z_{0 \mathrm{~h}}$ & roughness length for heat and moisture $[\mathrm{m}]$ & \\
\hline$\alpha$ & surface albedo $[-]$ & \\
\hline$g_{\mathrm{D}}$ & exponent for $V P D$ response & \\
\hline$h$ & initial ABL height $[\mathrm{m}]$ & 200.0 \\
\hline$\theta$ & initial mixed-layer potential temperature $[\mathrm{K}]$ & $T_{\text {input }}$ \\
\hline$\Delta \theta$ & initial temperature jump at $h[\mathrm{~K}]$ & $T_{\text {input }}+5$ \\
\hline$\gamma_{\theta}$ & free-atmosphere potential temperature lapse rate $\left[\mathrm{K} \mathrm{m}^{-1}\right]$ & 0.006 \\
\hline$A_{\theta_{\mathrm{v}}}$ & entrainment ratio for virtual potential temperature $[-]$ & 0.2 \\
\hline$q$ & initial mixed-layer specific humidity $\left[\mathrm{kg} \mathrm{kg}^{-1}\right]$ & $\mathrm{RH}=0.7$ \\
\hline$\Delta q$ & initial specific humidity jump at $h\left[\mathrm{~kg} \mathrm{~kg}^{-1}\right]$ & -0.002 \\
\hline$u$ & initial mixed-layer wind speed $\left[\mathrm{m} \mathrm{s}^{-1}\right]$ & 7.0 \\
\hline$u_{\mathrm{g}}$ & geostrophic wind speed $\left[\mathrm{m} \mathrm{s}^{-1}\right]$ & 10.0 \\
\hline
\end{tabular}


Acknowledgements. A. J. Teuling acknowledges financial support from the Netherlands Organization for Scientific Research through Veni grant 016.111.002. The authors acknowledge the constructive comments of Linda Schlemmer and Anneke van de Boer on this manuscript.

The service charges for this open access publication have been covered by the Max Planck Society.

Edited by: C. A. Williams

\section{References}

Anderson, R. G., Canadell, J. G., Randerson, J. T., Jackson, R. B., Hungate, B. A., Baldocchi, D. D., Ban-Weiss, G. A., Bonan, G. B., Caldeira, K., Cao, L., Diffenbaugh, N. S., Gurney, K. R., Kueppers, L. M., Law, B. E., Luyssaert, S., and O'Halloran, T. L.: Biophysical considerations in forestry for climate protection, Front. Ecol. Environ., 9, 174-182, 2010.

Bonan, G. B.: Forests and climate change: forcings, feedbacks, and the climate benefits of forest, Science, 320, 1444-1449, 2008.

Brilli, F., Hoertnagl, L., Hammerle, A., Haslwanter, A., Hansel, A., oreto, F., and Wohlfahrt, G.: Leaf and ecosystem response to soil water availability in mountain grasslands, Agric. For. Meteorol., 151, 1731-1740, 2011.

Christidis, N., Stott, P. A., Hegerl, G. C., and Betts, R. A.: The role of land use change in the recent warming of daily extreme temperatures, Geophys. Res. Lett., 40, 589-594, 2013.

Davin, E. L. and de Noblet-Ducoudré: Climatic impact of globalscale deforestation: radiative versus nonradiative processes, J. Climate, 23, 97-112, 2010.

Ek, M. B., Mitchell, K. E., Lin, Y., Rogers, E., Grunmann, P., Koren, V., Gayno, G., and Tarpley, J. D.: Implementation of NOAH land surface model advances in the National Centers for Environmental Prediction operational mesoscale Eta model, J. Geophys. Res., 108, D228851, doi:10.1029/2002JD003296, 2003.

Fischer, E. M., Seneviratne, S. I., Lüthi, D., and Schär: Contribution of land-atmosphere coupling to recent European summer heat waves, Geophys. Res. Lett., 34, L06707, doi:10.1029/2006GL029068, 2007.

Hill, T. C., Williams, M., and Moncrieff, J. B.: Modeling feedbacks between a boreal forest and the planetary boundary layer, J. Geophys. Res., 113, D15122, doi:10.1029/2007JD009412, 2008.

IPCC: Climate Change 2013: The Physical Science Basis. Contribution of Working Group I to the Fifth Assessment Report of the Intergovernmental Panel on Climate Change, Cambridge University Press, Cambridge, United Kingdom and New York, NY, USA, 2013.

Jarvis, P. G.: The interpretation of the variations in leaf water potential and stomatal conductance found in canopies in the field, Philos. Trans. Roy. Soc. London B, 273, 593-610, 1976.

Mahrt, L.: Surface heterogeneity and vertical structure of the boundary layer, Bound.-Layer Meteor., 96, 33-62, 2000.
Miralles, D. G., van den Berg, M. J., Teuling, A. J., and de Jeu, R. A. M.: Soil moisture-temperature coupling: a multiscale observational analysis, Geophys. Res. Lett., 39, L21707, doi:10.1029/2012GL053703, 2012.

Miralles, D. G., Teuling, A. J., van Heerwaarden, C. C., and de Arellano, V.-G.: Mega-heatwave temperatures due to combined soil desiccation and atmospheric heat accumulation, Nat. Geosci., 7, 345-349, 2014.

Monteith, J. L.: Evaporation and environment, Symp. Soc. Exp. Biol., XIX, 1965.

Monteith, J. L.: A reinterpretation of stomatal response to humidity, Plant, Cell Environ., 18, 357-364, 1995.

Noilhan, J. and Mahfouf, J.-F.: The ISBA land surface parameterisation scheme, Glob. Plan. Change, 13, 145-159, 1996.

Oren, R., Sperry, J. S., Katul, G. G., Pataki, D. E., Ewers, B. E., Phillips, N., and Schäfer, K. V. R.: Survey and synthesis of intraand interspecific variation in stomatal sensitivity to vapour pressure deficit, Plant, Cell Environ., 22, 1515-1526, 1999.

Paulson, C. A.: The mathematical representation of wind speed and temperature profiles in the unstable atmospheric surface layer, J. Applied Met., 9, 857-861, 1970.

Raupach, M. R.: Equilibrium evaporation and the convective boundary layer, Bound.-Layer Meteor., 96, 107-141, 2000.

Raupach, M. R.: Combination theory and equilibrium evaporation, Quart. J. Roy. Meteor. Soc., 127, 1149-1181, 2001.

Seneviratne, S. I., Corti, T., Davin, E., Hirschi, M., Jaeger, E. B., Lehner, I., Orlowsky, B., and Teuling, A.: Investigating soil moisture-climate interactions in a changing climate: A review, Earth-Sci. Rev., 99, 125-161, 2010.

Stap, L. B., van den Hurk, B. J. J. M., van Heerwaarden, C. C., and Neggers, R. A. J.: Modelled contrast in the response of the surface energy balance to heatwaves for forest and grassland, J. Hydrometeor., 15, 973-989, 2014.

Streck, N. A.: Stomatal response to water vapor pressure deficit: an unsolved issue, Curr. Agricult. Sci. Technol., 9, 317-322, 2003.

Tennekes, H.: A model for the dynamics of the inversion above a convective boundary layer, J. Atmos. Sci., 30, 558-567, 1973.

Teuling, A. J., Seneviratne, S. I., Stäckli, R., Reichstein, M., Moors, E., Ciais, P., Luyssaert, S., van den Hurk, B., Ammann, C., Bernhofer, C., Dellwik, E., Gianelle11, D., Gielen, B., Grünwald, T., Klumpp, K., Montagnani, L., Moureaux, C., Sottocornola, M., and Wohlfahrt, G.: Contrasting response of European forest and grassland energy exchange to heatwaves, Nat. Geosci., 3 , 722-727, 2010.

van de Boer, A., Moene, A. F., Graf, A., Simmer, C., and Holtslag, A. A. M.: Estimation of the refractive index structure parameter from single-level daytime routine weather data, Appl. Opt., 53, 5944-5960, 2014.

van Heerwaarden, C. C., Vilà-Guerau de Arellano, J., Moene, A. F., and Holtslag, A. A. M.: Interactions between dry-air entrainment, surface evaporation and convective boundary layer development, Quart. J. Roy. Meteor. Soc., 135, 1277-1291, 2009.

van Heerwaarden, C. C., Vilà-Guerau de Arellano, J., Gounou, A., Guichard, F., and Couvreux, F.: Understanding the daily cycle of evapotranspiration: a method to quantify the influence of forcings and feedbacks, J. Hydrometeor., 11, 1405-1422, 2010a. 
van Heerwaarden, C. C., Vilà-Guerau de Arellano, J., and Teuling, A. J.: Land-atmosphere coupling explains the link between pan evaporation and actual evapotranspiration trends in a changing climate, Geophys. Res. Lett., 37, L21401, doi:10.1029/2010GL045374, 2010b.

Vilà-Guerau de Arellano, J., van Heerwaarden, C. C., and Lelieveld, J.: Modelled suppression of boundary-layer clouds by plants in a CO2-rich atmosphere, Nat. Geosci., 5, 701-704, 2012.
Zaitchik, B. F., Macalady, A. K., Bonneau, L. R., and Smith, R. B.: Europe's 2003 heat wave: A satellite view of impacts and landatmosphere feedbacks., Int. J. Climatol., 26, 743-769, 2006. 